\title{
The physiological, transcriptional and genetic responses of an ozone- sensitive and an ozone tolerant poplar and selected extremes of their $F_{2}$ progeny
}

\author{
Nathaniel Robert Street ${ }^{\mathrm{a}, 1}$, Tallis Matthew James ${ }^{\mathrm{a}, 2}$, Tucker James ${ }^{\mathrm{a}, 2}$, Brosché Mikael ${ }^{\mathrm{b}}$, \\ Kangasjärvi Jaakko ${ }^{\mathrm{b}}$, Broadmeadow Mark ${ }^{\mathrm{c}}$, Gail Taylor ${ }^{\mathrm{a}, *}$

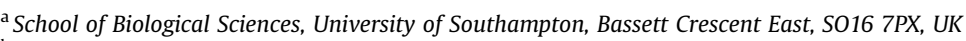 \\ ${ }^{\mathrm{b}}$ Plant Biology, Department of Biological and Environmental Sciences, University of Helsinki, FIN-00014 Helsinki, Finland \\ ${ }^{\mathrm{c}}$ Environmental Research Branch, Forest Research, Alice Holt Lodge, Farnham, Surrey GU10 4LH, UK \\ Ozone-responsive transcriptional changes and genetic control were studied in Populus plants with contrasting ozone sensitivity.
}

\section{A R T I C L E I N F O}

\section{Article history:}

Received 2 July 2010

Received in revised form

13 September 2010

Accepted 19 September 2010

\section{Keywords:}

Populus

Ozone stress

Microarray

Gene expression

QTL

\begin{abstract}
A B S T R A C T
Relatively little is known about the transcriptional response or genetic control of response and adaptation of trees to tropospheric ozone exposure. Such understanding is needed as up to $50 \%$ of forests, globally, may be subjected to phytotoxic concentrations of ozone. The physiological, transcriptional and genetic response to ozone was examined in Populus trichocarpa and P. deltoides, which show extreme sensitivity and tolerance to ozone, respectively. Using an inbred $F_{2}$ mapping population derived from these two species, we mapped quantitative trait loci (QTL) for traits associated with ozone response, examined segregation of the transcriptional response to ozone and co-located genes showing divergent responses between tolerant and sensitive genotypes with QTL. QTL were identified linking detrimental effects of ozone with leaf and biomass traits and differential responses were found for key genes involved in ethylene production and response.
\end{abstract}

(c) 2010 Published by Elsevier Ltd.

\section{Introduction}

Tropospheric ozone concentrations have increased by $\sim 38 \%$ since industrial times (Denman et al., 2007) and Fowler et al. (1999) predicted that up to $50 \%$ of forests will be exposed to $60 \mathrm{~nL} \mathrm{~L}^{-1}$ ozone by 2100 , a concentration known to damage plants (Miller et al., 1963). For agricultural and forest ecosystems, tropospheric ozone is considered the most widespread and damaging pollutant (Lindroth, 2010; Wittig et al., 2009). Karnosky et al. (2005) reported the long-term effects of ozone pollution on several tree species, and demonstrated a negative impact throughout the whole ecosystem, not only on the trees themselves but also on associated pests and soil microorganisms.

Stomata regulate the entry of ozone into the leaf (Vahisalu et al., 2008), and when ozone reaches the apoplast, production of toxic reactive oxygen species (ROS) is initiated (Mahalingam et al., 2006; Wohlgemuth et al., 2002). Symptoms range from accelerated senescence (Karnosky et al., 1996) and a decrease in growth rate

\footnotetext{
* Corresponding author.

E-mail address: g.taylor@soton.ac.uk (G. Taylor).

1 Present address: NR Street: Umeå Plant Science Centre, Department of Plant Physiology, University of Umeå, SE-901 87 Umeå, Sweden.

2 Both authors contributed equally to this work.
}

(Karnosky et al., 1996, 2005; Wittig et al., 2009), to foliar injury manifested as necrotic lesions analogous to those formed during the hypersensitive response (HR) (Langebartels et al., 2002). Concomitant with these symptoms is an up-regulation of defence and stress related genes and compounds (Conklin and Last, 1995; Lindroth, 2010; Ludwikow et al., 2004), and a down-regulation of photosynthetic components (Conklin and Last, 1995; Glick et al., 1995). Although transcriptional responses to ozone and underlying QTL have been studied in annual model and non-model species (Frei et al., 2008; Li et al., 2006; Overmyer et al., 2008; Puckette et al., 2008), there is currently limited knowledge in perennials, such as trees, which form the keystone species of many terrestrial ecosystems.

Populus has long been a commercially important genus, with diverse uses such as timber, pulp and paper, carbon sequestration, a biofuel feedstock and bioremediation. More recently it has joined the league of model organisms (Brunner et al., 2004; Taylor, 2002; Wullschleger et al., 2002) and is the first tree to have a fully sequenced genome (Tuskan et al., 2006). Microarrays constructed from Populus EST collections provide the opportunity to probe the transcriptional response to ozone in Populus, a perennial deciduous tree. In a recent meta-analysis Populus also exhibited similar responses in terms of biomass loss to a number of major keystone forest species (Wittig et al., 2009). 
Here, we examined the genetic and genomic responses of Populus to chronic and acute ozone exposure. We investigated the genetics and genomics of response to ozone in two divergent Populus species and their inbred $\mathrm{F}_{2}$ progeny in two experiments. In the first chambered field study, sensitive and tolerant ozone genotypes of the $F_{2}$ population were identified and QTL for ozone response determined. These were studied in more detail, alongside the grandparental species in controlled environments using a transcriptomics approach.

\section{Materials and methods}

\subsection{Chronic ozone exposure}

\subsubsection{Growth chambers and ozone regime}

The experiment was conducted in 16 glass chambers at the Forest Research closed nursery site at Headley, Hampshire, UK (described in Broadmeadow et al., 1999; Broadmeadow and Jackson, 2000). Eight chambers were ozone enriched, and eight exposed to ambient air. Prior to planting, dolomitic lime, base dressing and slow release Osmocote (15:9:12) fertiliser were applied at the recommended dose. Plants were irrigated daily by overhead sprinklers $\left(\sim 12 \mathrm{~L} \mathrm{~h}^{-1}\right.$ for $30 \mathrm{~min}$ from 07:00-07:30, and from 19:00-19:30). Airflow was approximately $0.57 \mathrm{~m}^{3} \mathrm{~s}^{-1}$ in all chambers, equating to approximately two air changes $\mathrm{min}^{-1}$ reduced to approximately $0.28 \mathrm{~m}^{3} \mathrm{~s}^{-1}$ between 20:00 and 10:00. Day length was not controlled. Ozone was generated by electrical discharge, using a model B063 Odotrol generator (Wallace \& Tiernan, Kent, UK) and ozone was passed through a water trap to remove $\mathrm{N}_{2} \mathrm{O}_{5}$ (Broadmeadow and Jackson, 2000). Ozone concentration was measured optically (model 8810, Monitor Labs, California, USA). Needle valves were used to balance the flow to each chamber. The exposure regime consisted of a square waveform fumigation with ozone exposure occurring between 11:00-18:00 from 2004-0714-2004-10-20. Mean ozone concentration in treatment chambers were $93.1 \mathrm{~nL} \mathrm{~L}^{-1}$ during fumigation and was $7.9 \mathrm{~nL} \mathrm{~L}^{-1}$ outside the fumigation period (i.e. at night). Mean ozone concentration in control chambers was $16.7 \mathrm{~nL} \mathrm{~L}^{-1}$ during fumigation, and $7.9 \mathrm{~nL} \mathrm{~L}^{-1}$ outside the fumigation period. Within treatment chamber variability was tested by ANOVA no significant difference was found (data not shown).

\subsubsection{Plant material}

An inbred $F_{2}$ mapping population (Family 331), formed from a cross between Populus trichocarpa Torr. \& Gray (93-968) and P. deltoides Bart (ILL-129), known to be highly divergent for a vast range of phenotypic traits was developed by Bradshaw et al. (1994). This pedigree was imported into the UK in 1999 (see Rae et al., 2009 for details). Hardwood cuttings used in this study were obtained from a field site in Hampshire, UK (see Rae et al., 2004 for details). Cuttings of uniform length and that were of uniform diameter within each genotype (i.e. cutting diameter between genotypes was as consistent as possible but may vary but within genotype all diameters were uniform) were stored at $2{ }^{\circ} \mathrm{C}$ until required. Three replicates of 164 $\mathrm{F}_{2}$ genotypes and the $P$. trichocarpa and $P$. deltoides grandparents were each assigned within the eight chambers ensuring that replicates of each genotype were distributed evenly across the chambers. The pattern was repeated for the ambient and treated groups. Cuttings were soaked in cold water for $24 \mathrm{~h}$ prior to planting and were planted on 2004-06-04 in rows $25 \mathrm{~cm}$ apart with two viable buds above the soil surface. Plants were sprayed with Ambush on 2004-06-22 to control beetle damage, and with Cypermethrin on 2004-09-24 for spider mite. Plants were grown for 33 days before the ozone treatment was initiated.

\subsubsection{Acute ozone exposure}

Described in Supplementary materials and methods.

\subsubsection{Trait measurements}

Described in Supplementary materials and methods.

\subsubsection{Data analysis}

Data were analysed using GLM-ANOVA models in Minitab 14 (Minitab, Coventry, UK) and where necessary data were normalised using a Box-Cox transformation (Box and Cox, 1964). An initial ANOVA was performed to test for chamber and position within chambers effects. As these factors were not significant, they were eliminated from the model. Genotype, treatment and interaction effects were tested using the model (5)

$Y_{i j k}=\mu+G_{i}+T_{j}+G \times T_{i j}+\varepsilon_{i j k}$

where $\mu$ is the general mean, $G_{i}$ is the genotype effect (random), $T_{j}$ is the treatment effect (fixed), $G \times T_{i j}$ is the genotype by treatment interaction and $\epsilon_{i j k}$ is the error.

\subsubsection{QTL mapping}

All genotypes used for QTL mapping were full-sib progeny (referred to here as the $F_{2}$ generation) of Family 331. QTL were mapped using the freely available web- based program QTLExpress (Seaton et al., 2002) using the out-breeding module. Permutation testing implemented in QTLExpress was used to establish the critical F value for declaring a QTL present (1000 permutation, see Churchill and Doerge, 1994). QTL confidence intervals (CIs) were calculated using an F-two drop-off (the cM distance taken for the peak $F$ value to drop by two). The genetic linkage map used was produced by Tuskan et al. (pers. comm.) and consists of 91 SSR markers genotyped on 350 of the full-sib progeny and 92 fully informative Amplified Fragment Length Polymorphisms (AFLPs) genotyped on 165 genotypes of the progeny. The resulting genetic map consists of 22 Linkage Groups (LG). Where more than one LG has been assigned to a chromosome, they are numbered with the LG number and a letter, letter order indicates the order of LGs along the chromosome. SSR primer sequences (http://www.ornl.gov/sci/ipgc/ssr_resource. $\mathrm{htm}$ ) were located on the genome sequence to align the genetic and physical maps and to provide correct orientation of linkage groups (i.e. $3^{\prime}$ to $5^{\prime}$ ). The location information of SSR markers was used to generate gene lists of all genes between flanking SSR markers of a subset of QTL. QTL figures were produced using a custom-written $R$ package developed by ourselves and available on request. This package implements a permutation test and sliding window approach to identify regions of the genetic map over-represented with co-locating QTL (See Kliebenstein et al., 2006). For each permutation, QTL are randomly shuffled across the genome and a sliding window of $5 \mathrm{cM}$ is then used to count the number of QTL in each window region. The window was advanced in $1 \mathrm{cM}$ steps across the entire genetic map and the maximum number of QTL in a window region was recorded per permutation. The permutation maximum count results were then sorted and used to determine the critical value at an $\alpha 0.05$ significance level (the 950th value for 1000 permutations). The sliding window was then applied to the original QTL data to identify regions with more than the critical number of co-locating QTL. The critical number for our data was five (1000 permutations).

\subsection{Transcriptional response to acute ozone}

\subsubsection{P. trichocarpa and $P$. deltoides grand parental species}

After nine hrs of ozone exposure, one plant of each species was sampled from each chamber, with an additional $P$. trichocarpa sample taken from a randomly chosen chamber, giving a total of five replicates for $P$. trichocarpa and four for $P$. deltoides for both treated and control. The fifth leaf below the first fully unfurled leaf was frozen in liquid $\mathrm{N}_{2}$ for RNA extraction. Total RNA was extracted as described in Street et al. (2006). RNA concentration was determined using an Eppendorf Biophotometer (Eppendorf, Hamburg, Germany), and quality was assessed using a $1 \%(\mathrm{w} / \mathrm{v})$ agarose gel.

The microarrays used are described in Brosché et al. (2005) and were performed as described there. The constructed cDNA libraries were derived from $P$. euphratica grown in Ein Advat Valley, Israel, and also from control and stress exposed trees. From these libraries, 8153 ESTs were spotted on poly-lysine slides (Brosché et al., 2005).

\subsubsection{Analysis of sensitive and tolerant genotypes}

Leaf sampling was carried out as described above. For each sampled leaf a digital image was taken and the percentage coverage of ozone-induced necrosis was estimated.

RNA was extracted as described above. Equal amounts of RNA from the five replicates of each genotype for each treatment were pooled to give $100 \mu \mathrm{g}$ total RNA per treatment and genotype to be used for cDNA synthesis. One slide was hybridised per genotype with each slide co-hybridising the control and treated samples for that genotype. This experimental design gives a replication of three for each ozone response group (one genotype represents one biological replicate), with each of those three replicates representing a pool. As our intention was to test for differences between the two ozone response groups, we felt that this pooling strategy was suitable and still maintained replication at the comparison level of interest (i.e. tolerant vs. sensitive). However, we acknowledge that our results only infer differences at this level.

The poplar PICME microarray (www.picme.at) consisting of 26,915 ESTs including all those used for the grandparental acute ozone study was used for this experiment. The ESTs printed on the PICME poplar arrays were produced by INRANancy (Rinaldi et al., 2007), INRA-Orleans (Déjardin et al., 2004), and University of Helsinki (Brosché et al., 2005) within the framework of the LIGNOME and ESTABLISH programme respectively. Full MIAME-compliant details of the array content and production can be found at www.picme.at (also see below). Probes were prepared and labelled as for the grandparental experiment (see Brosché et al., 2005 for details). All array data generated has been deposited in the Gene Expression Omnibus (GEO) database as superSeries GSE10932. Full hybridisation and analysis methods are available as part of this submission.

\subsubsection{Microarray data analysis}

Intensity values were print-tip LOWESS normalised to control for within-array signal intensity artefacts and cross-slide normalisation was also applied to ensure consistency of scale. See Smyth and Speed (2003) for a review of microarray normalisation. Differentially expressed ESTs between control and ozone-exposed treatments were identified using the 'B statistics' as described in Tallis et al. (2010). 
We used an FDR-adjusted $p$ value of 0.05 as our threshold for declaring an EST as differentially expressed.

The list of significantly differentiated ESTs was then median-aggregated on a gene model basis to yield a final list of differentially expressed genes. ESTs were assigned to 'Jamboree' gene models from v1.1 of the P. trichocarpa 'Nisqually-1' genome sequence (http://genome.jgi-psf.org/Poptr1_1/Poptr1_1.home. html) based on filtered BLAT (Kent, 2002) alignments. ESTs with low BLAT scores were removed to avoid incorrect assignment to gene models. Arabidopsis thaliana orthologs were then identified by BLASTp searches of the predicted Populus gene model protein sequences against the protein sequences in TAIR release 7 (The Arabidopsis Information Network, www.Arabidopsis.org). Results with low BLASTp scores were left blank to indicate that no ortholog could be identified.

To identify genes with differential expression between the tolerant and sensitive $\mathrm{F}_{2}$ genotype groups, Partial Least Squares Discriminant Analysis (PLS-DA) was performed in the software package SIMCA P (Umetrics Ltd, Windsor, UK). Normalised data were imported and scaled by mean centring. A Variable Importance (VIP) score was generated for each EST on its ability to explain the separation between groups. The top 50 ESTs were taken to be differentially expressed, and all exceeded a VIP score of 2 . This list was then aggregated to representative gene models for the purpose of examining QTL co-location.

Functional over-representation analysis was performed using the BiNGO plugin (Maere et al., 2005) for the network visualisation software Cytoscape (version 2.5.1, Shannon et al., 2003). We used the hypergeometric test and set a Benjamini and Hochberg FDR-adjusted significance level of 0.05 for declaring a GO (Gene Ontology, www.geneontology.org) category as significantly over-represented. As there is not yet a mature GO release for Populus, we used the best BLASTp hit results of predicted Populus gene models to A. thaliana to infer GO using the TAIR 7 release of the A. thaliana genome. Tests were performed using the Arabidopsis thaliana GO-plantslim ontology.

Expression data from the microarray analysis was validated for selected targets using RT-qPCR, this is described in the Supplementary materials and methods.

\section{Results and discussion}

\subsection{P. deltoides and P. trichocarpa grandparents show contrasting responses to acute and chronic ozone exposure}

Acute ozone exposure induced marked differences in visible symptoms between the two grandparental species (Fig. 1a). P. trichocarpa leaves began to develop lesions within nine hours which spread and blackened with further exposure. No such symptoms were observed in $P$. deltoides at any time point. Chronic fumigation significantly increased the percentage of abscised leaves in both species, but to a greater extent in P. deltoides on day 30 . Ozone significantly reduced chlorophyll content in $P$. deltoides, with a slight non-significant increase shown for $P$. trichocarpa.

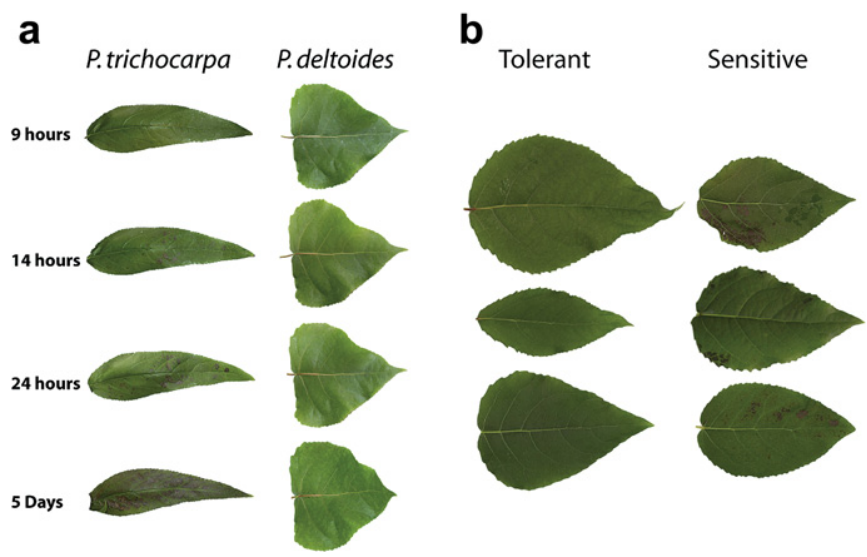

Fig. 1. a The progression of ozone damage for P. deltoides and $P$. trichocarpa exposed to $200 \mathrm{~nL} \mathrm{~L}^{-1}$ ozone in growth chambers for 5 days, showing necrotic lesion formation in P. trichocarpa, with a lack of visible symptoms in $P$. deltoides. b The response of three ozone tolerant and three sensitive $F_{2}$ genotypes of Family 331 to a $9 \mathrm{~h}$ exposure of $200 \mathrm{~nL} \mathrm{~L}^{-1}$ ozone in growth chambers, showing necrotic lesions in the sensitive clones.
For growth traits, there was generally a negative effect of ozone, with height, diameter, leaf number, and leaf expansion rate all showing a decrease in both grandparental species (Table 1). P. trichocarpa exhibited considerably more visible damage than $P$. deltoides, with $51 \%$ of leaves showing characteristic ozone damage, compared to $0 \%$ for $P$. deltoides. Lesion morphology was similar to that seen in the acute treatment suggesting that the same physiological response is involved in the formation of lesions in both chronic and acute treatments. These results suggest that the two grandparental species show significantly different responses to ozone exposure. The rapidly spreading lesion morphology of $P$. trichocarpa that resulted in complete death of leaves was striking, especially in contrast to the $P$. deltoides grandparent.

\subsection{An $F_{2}$ mapping pedigree exposed to a chronic ozone treatment}

For all traits, there was a highly significant effect of genotype $(p<0.0001$; Table 2). No significant ozone effect on height was found but in contrast for basal stem diameter a small $(-3.2 \%)$ but significant negative effect $\left(F_{1,132}=11.24, p<0.001\right)$ of ozone was found similar to that reported in a meta-analysis of forest tree ozone responses (Wittig et al., 2009), indicating that ozone exposure is likely to impact biomass yield. This will require further confirmatory analysis from longer-term studies, but suggests that Populus biomass yield is likely to be detrimentally affected by future increased ozone concentrations, which are consistent with previous reports (Bohler et al., 2007; Bortier et al., 2000; Karnosky et al., 1996; Wittig et al., 2009; Woo and Hinckley, 2005). Such decreases in productivity are likely to be related to decreased photosynthetic activity (Bortier et al., 2000; Coleman et al., 1995; Degl'Innocenti et al., 2007; Lorenzini et al., 1999) and reduced leaf area (Wittig et al., 2009).

Ozone had a positive influence on the total number of leaves initiated both early $\left(F_{1,123}=4.62, p<0.05\right)$ and late $\left(F_{1,126}=5.45\right.$, $p<0.05)$ in the season. The area of the first unfurled leaf was significantly greater in ozone $\left(F_{1,93}=6.82, p<0.01\right)$, whilst leaf area expansion rate was significantly reduced $\left(F_{1,93}=7.82, p<0.01\right)$. No significant effect on final leaf area was found. There was a highly significant increase in leaf abscission. Chlorophyll content and late percentage abscission (70d) showed significant genotype*treatment interaction, suggesting that differential response mechanisms exist within the $\mathrm{F}_{2}$ genotypes (Table 2 ).

Table 1

Summary of traits measured in P. deltoides and P. trichocarpa in response to a chronic $100 \mathrm{~nL} \mathrm{~L}^{-1}$ ozone treatment. Where traits were measured on more than one occasion, this is indicated by $30 \mathrm{~d}$ and $70 \mathrm{~d}$ ( 30 or 70 days of exposure). The data represent means for each trait recorded in ambient conditions and elevated ozone, and the percentage effect of ozone upon the trait. A general linear model was used to analyse all data except \% abscised (30d) where a Kruskal-Wallis test was performed due to a non-normal distribution. Significance levels are indicated by ${ }^{*} p<0.05,{ }^{* *} p<0.01$, *** $p<0.001$.

\begin{tabular}{|c|c|c|c|c|c|c|c|c|}
\hline & \multicolumn{4}{|c|}{ P. deltoides } & \multicolumn{4}{|c|}{ P. trichocarpa } \\
\hline & Control & Ozone & $\%$ Effect & Trt & Control & Ozone & \% Effect & Trt \\
\hline Height $(\mathrm{cm})$ & 55.30 & 53.00 & -4.34 & ns & 79.30 & 72.30 & -9.68 & ns \\
\hline Diameter $(\mathrm{mm})$ & 6.03 & 5.43 & -10.00 & ns & 6.47 & 5.17 & -20.20 & $*$ \\
\hline Leaf number (30d) & 15.70 & 14.70 & -6.80 & ns & 19.70 & 15.30 & -28.76 & ns \\
\hline Leaf number (70d) & 21.30 & 18.30 & -16.39 & $*$ & 26.70 & 26.00 & -2.69 & ns \\
\hline Chlorophyll content & 15.10 & 9.53 & -58.45 & $* *$ & 20.70 & 21.90 & 5.48 & ns \\
\hline$\%$ Abscised (30d) & 7.10 & 17.60 & 59.66 & $* * *$ & 8.80 & 10.30 & 14.56 & $*$ \\
\hline$\%$ Abscised (70d) & 18.50 & 40.00 & 53.75 & $* * *$ & 22.80 & 53.90 & 57.70 & $* * *$ \\
\hline $\begin{array}{l}\text { Area of first unfurled } \\
\quad \text { leaf }(\mathrm{cm})\end{array}$ & 7.40 & 6.64 & -11.38 & $*$ & 9.94 & 12.62 & 21.20 & $*$ \\
\hline $\begin{array}{l}\text { Leaf expansion } \\
\quad \text { rate (\% increase) }\end{array}$ & 74.60 & 68.20 & -9.38 & ns & 87.20 & 54.40 & -60.29 & * \\
\hline
\end{tabular}


Table 2

Summary of traits measured in the $\mathrm{F}_{2}$ population in response to a chronic $100 \mathrm{~nL} \mathrm{~L}^{-1}$ ozone treatment. Where traits were measured on more than one occasion, this is indicated by $30 \mathrm{~d}$ and $70 \mathrm{~d}$ ( 30 or 70 days of exposure). The data represent means for each trait recorded in ambient conditions and elevated ozone, and the percentage effect of ozone upon the trait. A general linear model was used to analyse all data except \% abscised (30d) where a Kruskal-Wallis test was performed due to a nonnormal distribution. Significance levels are indicated by ${ }^{*} p<0.05,{ }^{* *} p<0.01$, *** $p<0.001$.

\begin{tabular}{|c|c|c|c|c|c|c|}
\hline & Control & Ozone & $\%$ effect & Trt & Geno & Geno*Trt \\
\hline Height $(\mathrm{cm})$ & 78.70 & 79.74 & 1.30 & ns & $* * *$ & $\mathrm{~ns}$ \\
\hline Diameter $(\mathrm{mm})$ & 7.09 & 6.57 & -3.20 & $* * *$ & $* * *$ & ns \\
\hline Leaf number (30d) & 19.60 & 20.30 & 3.44 & $*$ & $* * *$ & ns \\
\hline Leaf number (70d) & 26.10 & 27.15 & 3.84 & $* *$ & *** & ns \\
\hline Chlorophyll content & 21.06 & 21.22 & 0.78 & ns & *** & $*$ \\
\hline$\%$ abscised (30d) & 2.45 & 12.77 & 80.78 & *** & *** & NA \\
\hline$\%$ abscised (70d) & 14.59 & 33.24 & 56.11 & *** & *** & * \\
\hline Area of first unfurled leaf $(\mathrm{cm})$ & 10.56 & 11.81 & 10.60 & $*$ & *** & ns \\
\hline Leaf expansion rate (\% increase) & 99.80 & 90.70 & -10.03 & $* *$ & $*$ & ns \\
\hline
\end{tabular}

\subsection{QTL mapping in the $F_{2}$ population}

In total, 58 QTL were identified for 11 traits (Table 3) and were found on all linkage groups except VII and XVI. Individual QTL explained between 1.5 and $16.3 \%$ of phenotypic variance, with the lowest being for basal stem diameter in ozone on LG Vb, and the highest for visible damage in ozone (late season) on linkage group $\mathrm{X}$. These estimates of explained phenotypic variance represent over-estimates due to the Beavis effect (Utz et al., 2000; Xu, 2003). The average confidence interval span was $30 \mathrm{cM}$, with the smallest being $4 \mathrm{cM}$ for chlorophyll content in response to ozone on LG XVII.

Of the 58 QTL detected, 20 were found to map only under ozone treatment or as response QTL (indicated in bold in Table 3). It is likely that these represent genomic regions that are specifically involved in governing the response to ozone, and are the most encouraging QTL for further investigation. Such QTL were found for leaf necrosis, diameter, late-season leaf number, height, late season abscission, area of the first unfurled leaf and chlorophyll content, indicating that ozone responsive genomic regions exist that govern numerous traits.

A number of ozone stress responsive loci were mapped with colocating QTL for more than one trait, suggesting that these loci control adaptive response mechanisms that impact the general physiology of the plant. LGs III, IV, Vb, VI, X and XI all contain such examples. Three examples show co-location to QTL for basal diameter that were mapped only in the ozone treatment or as response (percentage response to ozone) QTL (Table 3). These loci warrant future attention as they appear to be those most likely to control the reduced diameter growth in response to ozone exposure.

\subsection{Sensitive and tolerant $F_{2}$ genotypes exposed to an acute ozone treatment}

The three most sensitive and three most tolerant genotypes were selected on the basis of visible damage and necrotic lesion development after 30 and 70 days of the chronic ozone exposure. No significant differences were seen between sensitivity groups for any of the traits except visible damage at 30 and 70 days and those relating to leaf size (Table 4). It is evident from the trait data for the sensitive and tolerant genotypes (Tables $1-3$ ) that the selection of $\mathrm{F}_{2}$ genotypes at the population extremes for the trait of interest (visible leaf damage) reduced the number of traits showing treatment responses to ozone exposure. This is in contrast to P. deltoides and $P$. trichocarpa, which exhibited differences for numerous traits besides visible damage. Removing the influence of other traits is
Table 3

QTL mapped for physiological traits using composite interval mapping on 164 genotypes of Family 331 in $100 \mathrm{~nL} \mathrm{~L}^{-1}$ ozone (T), ambient air (C), and percentage effect response to ozone (R), showing linkage group (LG) and centiMorgan position (position $(\mathrm{cM})$ ), the confidence interval of the QTL $(\mathrm{CI})$, the statistical significance of the QTL ( $p$ value) and the percentage phenotypic variance explained by the QTL (\% $\mathrm{Vp}$ ). Where traits were measured on two occasions, this is indicated by $30 \mathrm{~d}$ ( 30 days of exposure) or $70 \mathrm{~d}$ (70 days of exposure). Treatment abbreviations in bold indicate that the QTL were only mapped in T and/or R.

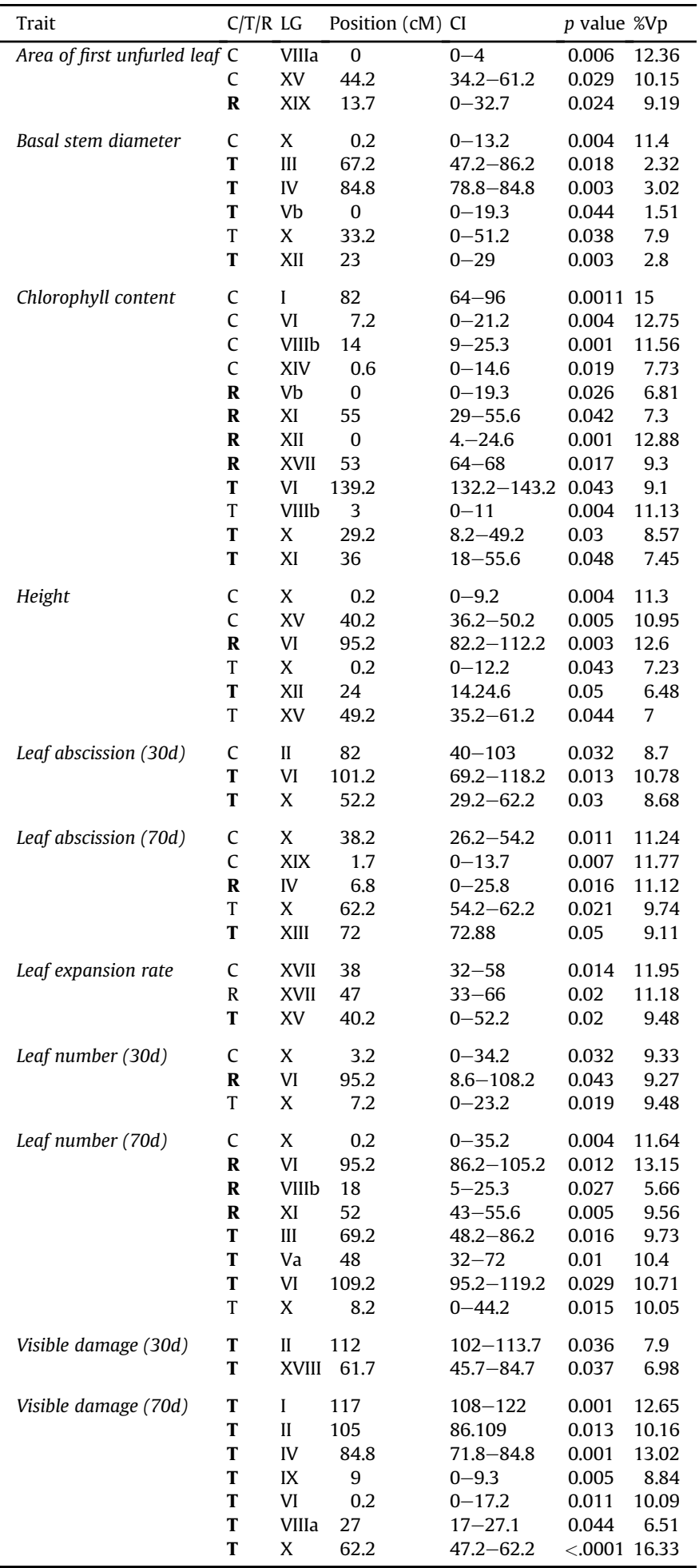


Table 4

Means of physiological traits for the selected sensitive and tolerant clones of Family 331, identified from a $100 \mathrm{~nL} \mathrm{~L}^{-1}$ ozone exposure in open top chambers. For traits measured on more than one occasion, this is indicated by 30d (30 days of exposure) and 70d (70 days of exposure). Results of ANOVA are given, with ${ }^{*} p<0.05$, ** $p<0.01,{ }^{* * *} \quad p<0.001$. $\mathrm{G}=$ genotype, $\mathrm{T}=$ treatment, $\mathrm{S}=$ sensitivity group, $\mathrm{TS}=$ interaction between treatment and sensitivity group, $\mathrm{TG}=$ interaction between treatment and genotype.

\begin{tabular}{|c|c|c|c|c|c|c|c|c|c|}
\hline & \multicolumn{2}{|l|}{ Control } & \multicolumn{2}{|l|}{ Ozone } & \multirow[t]{2}{*}{ G } & \multirow[t]{2}{*}{$\mathrm{T}$} & \multirow[t]{2}{*}{$\mathrm{S}$} & \multirow[t]{2}{*}{ TS } & \multirow[t]{2}{*}{ TG } \\
\hline & Tolerant & Sensitive & Tolerant & Sensitive & & & & & \\
\hline$\%$ Damaged 30d & - & - & 1.36 & 19.54 & - & - & $*$ & - & - \\
\hline \% Damaged 70d & - & - & 24.05 & 40 & - & - & $* *$ & - & - \\
\hline$\%$ Abscised 30d & 0.53 & 2.89 & 11.26 & 14.08 & ns & $*$ & ns & ns & $* *$ \\
\hline$\%$ Abscised 70d & 11.84 & 10.11 & 16.08 & 29.25 & ns & ns & ns & ns & $* *$ \\
\hline \% Necrotic & - & - & 0.18 & 23.23 & - & - & $* *$ & - & - \\
\hline Height $(\mathrm{cm})$ & 88.33 & 78.58 & 77.33 & 88.28 & ns & ns & ns & ns & ns \\
\hline Diameter (mm) & 8 & 6.94 & 6.53 & 6.97 & ns & ns & ns & ns & ns \\
\hline Chlorophyll content & 20.34 & 20.58 & 24.37 & 33.34 & * & $*$ & ns & ns & ns \\
\hline Leaf area $1\left(\mathrm{~cm}^{2}\right)$ & 9.52 & 6.4 & 7.91 & 12.34 & $* *$ & $* *$ & ns & $* * *$ & ns \\
\hline Leaf area $2\left(\mathrm{~cm}^{2}\right)$ & 22.21 & 13.31 & 14.14 & 21.8 & $*$ & ns & ns & $* *$ & ns \\
\hline$\%$ area increase & 134 & 116 & 81 & 84 & ns & $*$ & ns & ns & ns \\
\hline Leaf number $30 \mathrm{~d}$ & 23.45 & 21 & 20.5 & 23.87 & ns & ns & ns & ns & ns \\
\hline Leaf number 70d & 30.81 & 28 & 29.41 & 32.2 & ns & ns & ns & ns & ns \\
\hline
\end{tabular}

desirable when studying a single trait, in this case visible damage (Borevitz et al., 2003).

We were interested to see whether these genotypes would also separate as extremes when exposed to acute ozone. The sensitive genotypes showed more severe necrotic damage than $P$. trichocarpa. The tolerant clones remained symptom free (Fig. 1b) suggesting that, at the level of visible damage, these genotypes represent sensitivity extremes in response to both chronic and acute ozone damage.

\subsection{Stomatal conductance responses to ozone}

For the grandparents in the chronic exposure experiment, ozone treatment had no significant effect on stomatal conductance of young leaves. For semi-mature leaves, a significant treatment effect was found $(p<0.05)$. Both grand-parental species showed decreased stomatal conductance in response to acute ozone treatment $(p<0.03)$. P. deltoides showed a more rapid stomatal closure response with a significant decrease after three hours compared with nine hours for P. trichocarpa. However, after $28 \mathrm{~h}$ of exposure, there appeared to be a compensation response with conductance returning to control levels in both species. For the $F_{2}$ extreme genotypes under chronic ozone exposure, a significant treatment effect was found for semi-mature leaves, with ozone reducing conductance $(p<0.005)$. Conductance did not depend on sensitivity group, and there was no sensitivity group*treatment interaction (data not shown). For young leaves, no terms in the test were significant.

\subsection{Microarray analysis of the acute ozone response}

Both the grandparental species and the $F_{2}$ extreme sensitivity genotypes showed the most dramatic separation for visible damage in response to acute ozone exposure, their transcriptional response under this stress regime was examined.

Analysis of control-treatment response in the grandparental species identified 1409 genes as differentially expressed in response to ozone. 770 of the genes were up-regulated and 638 were down-regulated, with $\log _{2}$ fold-change in expression ranging from 3.1 to -3.5 (Table S1). We examined the Plant GO-Slim Gene Ontology (GO) categories of the up- and down-regulated ozone responsive genes to provide a broad overview of gene functions active in response to acute ozone exposure (Fig. S1a and b). Photosynthesis and plastid (chloroplast) function were the most represented down-regulated categories, as well as a decrease in metabolism categories such as protein biosynthesis and carbohydrate metabolism. The most represented up-regulated categories were those involved in biotic and abiotic stress responses, and secondary metabolism. Table 5 provides details of the 50 most significantly differentially expressed genes in response to ozone.

Analysis of control-treatment response in common to both $\mathrm{F}_{2}$ sensitivity groups of genotypes identified 813 genes as being differentially expressed in response to ozone (Table S2). Of these 477 were up- and 336 down-regulated, the $\log _{2}$ fold-change in expression ranged from 4.5 to -2.3 . We also performed an analysis of the response to ozone in each group of genotypes separately. This revealed that when considering only the tolerant genotypes, no genes were significant, whereas 1199 genes were significantly differentially expressed in the sensitive group. The range of $\mathrm{M}\left(\log _{2}\right.$ ratio) values was considerably smaller for the tolerant genotypes than for the sensitive ones (the sensitive genotypes had $M$ values ranging from 4.9 to -3.4 ). Fig. S1c and d shows the overlap for upand down-regulated genes respectively between the analysis of the two grandparents, the combined analysis of the two groups of $F_{2}$ genotypes, and the sensitive group alone. It is clear that although there was significant overlap between the different transcriptional responses, there was also clear separation between the grandparental responses and the response of the $\mathrm{F}_{2}$ sensitive and tolerant genotypes. Gene lists of the overlap between categories can also be found in Table S3. Visual examination of the tolerant genotype dataset revealed that the lack of significant genes was the result of a more inconsistent response across the three genotypes within this group (data not shown). This suggests that although these genotypes have similar leaf-level development of visible damage in response to ozone exposure, the development of those symptoms may result from different transcriptional mechanisms. A selection of four genes showed congruence between RT-qPCR and both microarray platforms for $P$. trichocarpa while this agreement was less for P. deltoides with expression patterns of two genes exhibiting variability between microarray platforms (Fig. S2)

\subsection{Genes with differential expression between ozone sensitivity genotypes}

Although it is likely that different transcriptional responses are involved in response to acute and chronic ozone exposure, we were interested to see whether any of the genes showing differential response patterns between the extreme genotypes co-located to mapped QTL. Table S4 details the 36 genes that showed the most significant divergence in response to ozone between the sensitive and tolerant genotypes, as identified using Partial Least-Squares Discriminant analysis. This is a supervised multivariate analysis method similar to PCA but where information on grouping is specifically provided. This method therefore maximises the separation between sample groups. Eleven genes were found to colocate to ozone treatment or response QTLs, including three on LG $X$ that co-locate to an identified hotspot of QTLs associated with height, leaf number and biomass (Table 3). The co-location of the diameter QTL specific to ozone treatment (LG X) within the same location as Populus Biomass Loci 3 (PBL-3) from Rae et al. (2009) suggests that ozone could have an interaction effect on the role of that QTL in biomass accumulation.

Fig. 2 shows a subset of linkage groups that contained genes that were differentially expressed in response to ozone between the sensitive and tolerant genotypes and that co-located to mapped QTL. Details of the genes presented in Fig. 2 can be found in Table 6 . 
Table 5

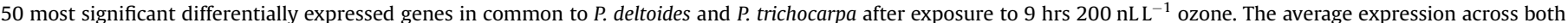

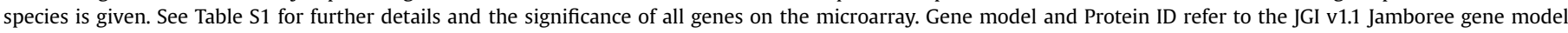

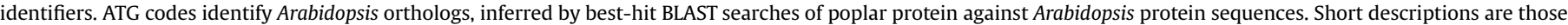
for Arabidopsis orthologs contained in TAIR 7.

\begin{tabular}{|c|c|c|c|c|c|}
\hline Gene Model & Protein ID & ATG & $\begin{array}{l}\log _{2} \text { fold } \\
\text { change }\end{array}$ & Adj. $P$ & Short description \\
\hline gw1.5570.1.1 & 290965 & AT1G76690 & -2.12 & 0.00018 & OPR2 (12-oxophytodienoate reductase 2 ) \\
\hline estExt_Genewise1_v1.C_1460016 & 745223 & AT3G14940 & -2.11 & 0.00034 & ATPPC3 (PHOSPHOENOLPYRUVATE CARBOXYLASE 3) \\
\hline estExt_fgenesh4_pm.C_1230010 & 837012 & АT3G02360 & -2.17 & 0.00035 & 6-phosphogluconate dehydrogenase family protein \\
\hline eugene 3.00040033 & 555320 & AT4G04640 & 2.01 & 0.00041 & ATPC1 (ATP synthase gamma chain 1 ) \\
\hline estExt_Genewise1_v1.C_LG_XIV0740 & 730849 & AT2G45290 & 1.33 & 0.00042 & transketolase, putative \\
\hline estExt_Genewise1_v1.C_LG_XI0270 & 726993 & AT4G27270 & -3.39 & 0.00045 & quinone reductase family protein \\
\hline estExt_fgenesh4_pg.C_1330041 & 828033 & AT5G27760 & -2.65 & 0.00047 & hypoxia-responsive family protein \\
\hline estExt_fgenesh4_pg.C_LG_X1392 & 822254 & АT3G08900 & -1.79 & 0.00053 & RGP3 (REVERSIBLY GLYCOSYLATED POLYPEPTIDE 3) \\
\hline estExt_fgenesh4_pg.C_LG_IX0475 & 821174 & AT2G21620 & -1.82 & 0.00053 & RD2 (RESPONSIVE TO DESSICATION 2) \\
\hline grail3.0189002602 & 663639 & AT1G26910 & -1.74 & 0.00053 & 60S ribosomal protein L10 (RPL10B) \\
\hline eugene3.00011774 & 549333 & AT5G11740 & -1.56 & 0.00053 & AGP15 (ARABINOGALACTAN PROTEIN 15) \\
\hline fgenesh4_pg.C_scaffold_29000012 & 796254 & AT1G72310 & -2.12 & 0.00053 & ATL3 (Arabidopsis T?xicos en Levadura 3) \\
\hline grail3.0155001302 & 673066 & AT5G15650 & -2.62 & 0.00053 & RGP2 (Reversibly glycosylated polypeptide) \\
\hline gw1.118.151.1 & 264663 & AT4G17030 & -2.50 & 0.00053 & ATEXLB1 (ARABIDOPSIS THALIANA EXPANSIN-LIKE B1) \\
\hline grail3.0025024002 & 668125 & AT5G01650 & -1.80 & 0.00053 & macrophage migration inhibitory factor family protein \\
\hline estExt_fgenesh4_pm.C_LG_XII0373 & 834364 & AT4G24990 & -2.08 & 0.00053 & ATGP4 (Arabidopsis thaliana geranylgeranylated protein) \\
\hline eugene3.00110215 & 568201 & AT5G54770 & -1.53 & 0.00067 & THI1 (THIAZOLE REQUIRING) \\
\hline eugene3.00181016 & 578792 & AT4G31985 & -1.90 & 0.00067 & 60S ribosomal protein L39 (RPL39C) \\
\hline estExt_fgenesh4_pg.C_21210001 & 829083 & AT1G14870 & -2.01 & 0.00067 & \\
\hline eugene3.00090275 & 557015 & AT3G12500 & -1.36 & 0.00067 & ATHCHIB (BASIC CHITINASE); chitinase \\
\hline estExt_Genewise1_v1.C_LG_II1841 & 710544 & AT4G02380 & 2.56 & 0.00067 & SAG21 (SENESCENCE-ASSOCIATED GENE 21) \\
\hline gw1.XII.485.1 & 422025 & AT3G22370 & -2.22 & 0.00068 & AOX1A (alternative oxidase $1 \mathrm{~A}$ ); alternative oxidase \\
\hline estExt_Genewise1_v1.C_1970084 & 746640 & AT5G24090 & -3.42 & 0.00071 & acidic endochitinase (CHIB1) \\
\hline gw1.XIV.108.1 & 243365 & AT5G43940 & -1.76 & 0.00080 & ADH2 (ALCOHOL DEHYDROGENASE 2) \\
\hline estExt_fgenesh4_pg.C_LG_I2142 & 815507 & AT3G27820 & -2.31 & 0.00083 & ATMDAR4 (MONODEHYDROASCORBATE REDUCTASE 4) \\
\hline gw1.X.2853.1 & 228156 & АT3G10420 & -2.37 & 0.00083 & sporulation protein-related \\
\hline estExt_fgenesh4_pg.C_LG_XV0035 & 824484 & AT5G54160 & -1.44 & 0.00083 & ATOMT1 (O-METHYLTRANSFERASE 1) \\
\hline estExt_Genewise1_v1.C_LG_X0765 & 724015 & AT1G02500 & 1.38 & 0.00083 & SAM1 (S-adenosylmethionine synthetase 1 ) \\
\hline estExt_fgenesh4_pg.C_LG_IV0366 & 817806 & AT1G29290 & -1.90 & 0.00083 & \\
\hline gw1.IX.2337.1 & 201872 & AT4G34200 & -3.40 & 0.00088 & EDA9 (embryo sac development arrest 9); \\
\hline fgenesh4_pg.C_scaffold_3758000001 & 792358 & AT1G58170 & -1.82 & 0.00088 & disease resistance-responsive protein-related \\
\hline eugene3.00100340 & 565782 & AT2G33470 & 2.18 & 0.00096 & GLTP1 (GLYCOLIPID TRANSFER PROTEIN 1) \\
\hline gw1.II.1221.1 & 409886 & AT4G01150 & -2.26 & 0.00096 & \\
\hline gw1.131.45.1 & 268043 & AT3G62020 & -1.78 & 0.00096 & GLP10 (GERMIN-LIKE PROTEIN 10) \\
\hline estExt_Genewise1_v1.C_LG_III0933 & 712009 & AT3G24170 & -1.37 & 0.00096 & ATGR1; glutathione-disulfide reductase \\
\hline estExt_fgenesh4_pm.C_LG_XIV0249 & 834831 & AT2G47000 & 1.79 & 0.00096 & PGP4 (P-GLYCOPROTEIN 4, P-GLYCOPROTEIN4) \\
\hline gw1.XIV.3318.1 & 246575 & AT2G05710 & -1.31 & 0.00097 & $\begin{array}{l}\text { aconitate hydratase, cytoplasmic, putative/citrate } \\
\text { hydro-lyase/aconitase, putative }\end{array}$ \\
\hline estExt_fgenesh4_pg.C_LG_VI0690 & 819178 & AT5G02160 & -3.15 & 0.00100 & \\
\hline estExt_Genewise1_v1.C_LG_III0308 & 711753 & AT1G64160 & 1.68 & 0.00100 & disease resistance-responsive family protein \\
\hline gw1.182.27.1 & 276236 & AT1G08170 & -2.13 & 0.00102 & histone H2B family protein \\
\hline gw1.IV.3246.1 & 198157 & AT1G67090 & 2.38 & 0.00106 & ribulose bisphosphate carboxylase small chain $1 \mathrm{~A}$ \\
\hline estExt_fgenesh4_pg.C_LG_V1224 & 818640 & AT1G06680 & 2.01 & 0.00106 & PSBP-1 (OXYGEN-EVOLVING ENHANCER PROTEIN 2) \\
\hline fgenesh4_pm.C_LG_XVI000502 & 808774 & AT1G23740 & -2.17 & 0.00106 & oxidoreductase, zinc-binding dehydrogenase family protein \\
\hline fgenesh4_pm.C_LG_IX000091 & 804044 & AT5G22770 & 2.54 & 0.00106 & ALPHA-ADR (ALPHA-ADAPTIN) \\
\hline estExt_Genewise1_v1.C_LG_XI1233 & 727425 & AT3G21690 & -1.61 & 0.00106 & MATE efflux family protein \\
\hline estExt_fgenesh4_pg.C_LG_IV0222 & 817755 & AT4G05020 & -1.93 & 0.00106 & NDB2 (NAD(P)H DEHYDROGENASE B2); disulfide oxidoreductase \\
\hline eugene3.00160400 & 576265 & AT1G24020 & -2.66 & 0.00106 & Bet v I allergen family protein \\
\hline estExt_fgenesh4_pg.C_LG_XIV1000 & 824336 & AT5G14780 & -1.43 & 0.00106 & FDH (FORMATE DEHYDROGENASE) \\
\hline gw1.XVIII.2487.1 & 261946 & AT4G29060 & 1.26 & 0.00111 & EMB2726 (EMBRYO DEFECTIVE 2726); translation elongation factor \\
\hline grail3.0018023401 & 646534 & AT4G22920 & 2.05 & 0.00126 & \\
\hline
\end{tabular}

Three genes co-located to a QTL for total damage (end-season damage) on LG I. These genes code for UDP-xyl synthase 5 (USX5), a tonoplast-intrinsic protein, and arabinogalactan protein 15. UDP-xyl synthase is involved in the production of many cell wall products as well as the upstream inhibition of enzymes (Harper and Bar-Peled, 2002). The tonoplast-intrinsic protein is a putative aquaporin, but of unknown function. Arabinogalactan proteins are extracellular proteoglycans that appear to have an as yet unexplained role in influencing cell proliferation (Schultz et al., 2000). Arabinogalactans have also been shown to be highly expressed in tension wood in poplar (Lafarguette et al., 2004). Their role there is suggested to be structural and it is highly probable that ozone is causing structural changes to cell wall components either directly or through the formation and action of free radicals (Fry et al., 2001) and thus inducing stress-associated cell wall re-modelling.
A gene encoding SAM Synthetase (SAMS), a gene involved in the production of ethylene, co-located to QTL for both late and early season visible damage on LG II and showed significant divergence in response between the extreme genotypes and the two grandparental species. S-adenosyl methionine (SAM) is the precursor molecule to both polyamines and ethylene (Langebartels et al., 1991; Pandey et al., 2000), both of which are thought to be involved in the response to ozone (Langebartels et al., 1991; Overmyer et al., 2005). It is of interest, therefore, that SAM Synthetase (SAMS) co-located to QTL for both late and early season visible damage on LG II. Pandey et al. (2000) put forward a hypothesis for the interacting role of polyamines and ethylene in the control of senescence, with ethylene acting as a positive regulator and polyamines as a negative regulator. The authors suggested a model in which polyamine and ethylene biosynthetic pathways 

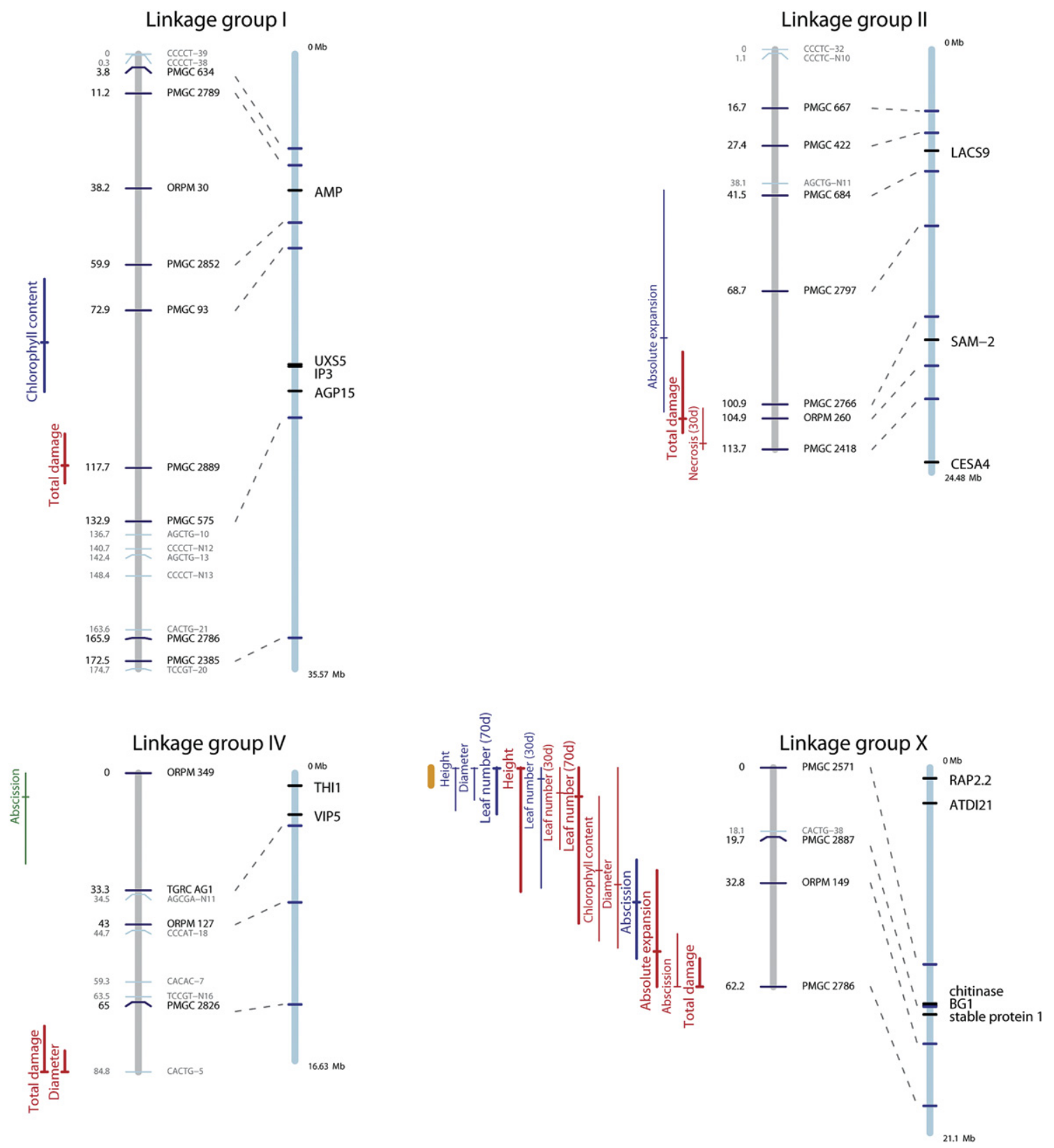

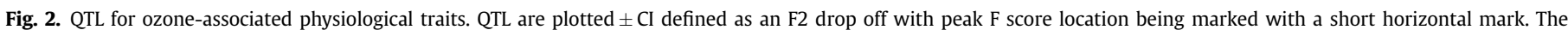

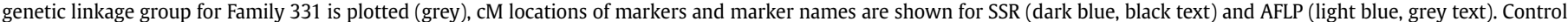

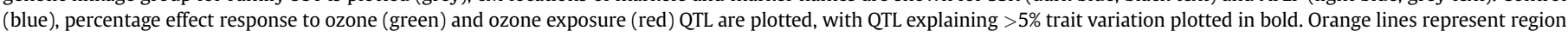

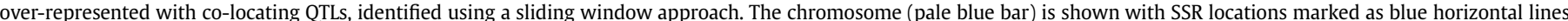

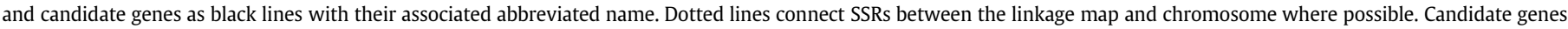

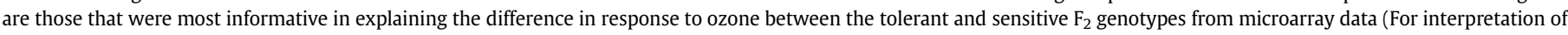
the references to color in this figure legend, the reader is referred to the web version of this article.).

compete for a limited pool of SAM, with the interaction between the two determining the outcome. They also postulated that the product of one pathway could act to inhibit the opposing pathway. This presents the intriguing possibility that a similar mechanism could exist in the response to ozone, with the interaction between polyamine and ethylene biosynthesis serving to determine the extent of visible damage.

Although lying outside the mapped QTL region on LG X, another gene (estExt_Genewise1_v1.C_LG_X3745) involved in ethylene response also showed significant divergence in response between the extreme genotypes and the two grandparental species. This ethylene response factor was down-regulated ( 2 fold) in both
$P$. deltoides and the tolerant extreme genotypes but was not differentially expressed in $P$. trichocarpa and was up-regulated in the sensitive genotypes. The direction of differential expression between both the grandparents and the sensitivity genotypes is particularly interesting considering the role of ethylene in ozone response shown in Overmyer et al. (2005) and Tamaoki et al. (2003a,b). Low-level ethylene production triggered stress responses more similar to pathogen induced responses while higher levels of ethylene production trigger lesion formation and propagation, a finding that is consistent with the expression changes observed in this study. A significant hotspot of co-locating QTL was found on LG X for early and late season leaf number, height 
Table 6

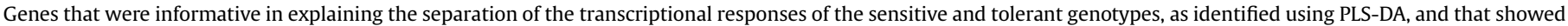

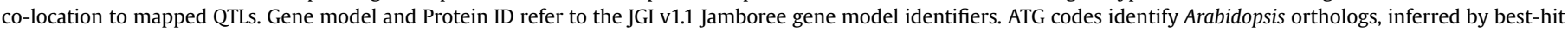
BLAST searches of poplar protein against Arabidopsis protein sequences. Short descriptions are those for Arabidopsis orthologs contained in TAIR 7.

\begin{tabular}{|c|c|c|c|c|c|c|}
\hline \multirow[t]{2}{*}{ Gene Model } & \multirow[t]{2}{*}{ Protein ID } & \multicolumn{2}{|c|}{ Log2 fold change } & \multirow[t]{2}{*}{ ATG } & \multirow[t]{2}{*}{ LG } & \multirow[t]{2}{*}{ Short description } \\
\hline & & Tolerant & Sensitive & & & \\
\hline estExt_Genewise1_v1.C_LG_I1353 & 706198 & 0.39 & 0.02 & AT3G46440 & I & UXS5 (UDP-Xyl synthase 5); catalytic \\
\hline eugene3.00011653 & 549212 & -0.71 & 2.45 & AT4G01470 & I & GAMMA-TIP3/TIP1;3 (tonoplast intrinsic protein $1 ; 3$ ) \\
\hline eugene3.00011774 & 549333 & 0.75 & 2.47 & AT5G11740 & I & AGP15 (ARABINOGALACTAN PROTEIN 15) \\
\hline grail3.0050014702 & 644907 & 2.05 & 0.06 & AT4G01850 & II & MAT2/SAM-2 (S-adenosylmethionine synthetase 2) \\
\hline estExt_fgenesh4_pg.C_LG_IV0080 & 817727 & -0.07 & -3.68 & AT5G54770 & IV & THI1 (THIAZOLE REQUIRING) \\
\hline eugene3.00040262 & 555549 & 5.73 & 1.93 & AT1G61040 & IV & VIP5 (VERNALIZATION INDEPENDENCE 5) \\
\hline gw1.VI.1805.1 & 417432 & -0.41 & 1.99 & AT3G22120 & VI & CWLP (CELL WALL-PLASMA MEMBRANE LINKER PROTEIN) \\
\hline estExt_fgenesh4_pg.C_LG_VIII1530 & 820835 & 5.80 & 3.82 & AT2G29420 & VIII & ATGSTU7 (GLUTATHIONE S-TRANSFERASE 25) \\
\hline estExt_Genewise1_v1.C_LG_X3745 & 725612 & -2.03 & 2.46 & AT3G14230 & $\mathrm{x}$ & RAP2.2; DNA binding/transcription factor \\
\hline estExt_fgenesh4_pg.C_LG_X0149 & 821723 & -1.34 & 1.29 & AT4G15910 & $\mathrm{X}$ & ATDI21 (Arabidopsis thaliana drought-induced 21) \\
\hline estExt_Genewise1_v1.C_LG_X0543 & 723883 & 0.01 & -1.34 & AT3G16920 & $\mathrm{X}$ & chitinase \\
\hline fgenesh4_pg.C_LG_X001297 & 769807 & 1.46 & 4.82 & AT3G57270 & $\mathrm{X}$ & BG1 (BETA-1,3-GLUCANASE 1 \\
\hline estExt_fgenesh4_pm.C_LG_X0585 & 833676 & -0.87 & -1.79 & AT3G17210 & $\mathrm{X}$ & stable protein 1 -related \\
\hline estExt_fgenesh4_pm.C_LG_XII0129 & 834247 & 1.43 & 0.97 & AT5G54160 & XII & ATOMT1 (O-METHYLTRANSFERASE 1) \\
\hline
\end{tabular}

and diameter. This hotspot co-locates to three genes that were differentially expressed between the two sensitivity groups; a chitinase gene, BG1 (BETA-1,3-GLUCANASE 1), and stable protein 1.

\section{Conclusion}

Ozone greatly increased the occurrence of visible damage, manifested as small flecks or larger necrotic spots, as observed in a range of species (Berrang et al., 1991; Heggestad and Middleton, 1959; Kargiolaki et al., 1991; Piikki et al., 2004). There was considerable variation in the extent of this damage, with some genotypes showing very little damage. In contrast, some genotypes had over $90 \%$ damaged leaves later in the season. The marked increase in leaf abscission is consistent with previous work (Bohler et al., 2007; Karnosky et al., 1996; Woo and Hinckley, 2005), and serves to demonstrate the detrimental effect of ozone on leaf biomass. The treatment specific co-location of QTL for leaf number, leaf abscission and visible leaf damage with basal diameter suggests that these may be the responses resulting in reduced diameter growth. Such an understanding of the genetic control leading to reduced biomass production is extremely useful for directing future research directions and breeding approaches. For example, Wittig et al. (2009) suggest that relative to preindustrial levels, current tropospheric ozone has already reduced Northern temperate and boreal forest productivity by $7 \%$, while future predictions suggest an $11 \%$ reduction by 2050 (Wittig et al., 2009). Concurrent to this, atmospheric carbon dioxide concentrations $\left(\left[\mathrm{CO}_{2}\right]\right)$ have increased $\sim 40 \%$ since preindustrial times and Karnosky et al. (2003) identified that for Populus at least, such future biomass reductions by ozone will be mitigated by increased atmospheric $\left[\mathrm{CO}_{2}\right]$.

Many of the differentially expressed genes identified here as being ozone-responsive, confirm previous studies on other species (Gupta et al., 2005; Li et al., 2006; Matsuyama et al., 2002; Puckette et al., 2008). Genes identified here are also more generally involved in abiotic stress responses. This suggests that at the global scale, induced gene responses are conserved across species and that there appears to be a conserved general abiotic stress-induced remodelling of the transcriptome, in response to a variety of stresses. Genes encoding enzymes involved in the phenylpropanoid pathway were up-regulated as a result of ozone exposure, as was found in similar studies in a range of species (Koch et al., 2000; Ludwikow et al., 2004; Matsuyama et al., 2002; Puckette et al., 2008). Re-modelling of secondary metabolism is apparently an important and conserved mechanism of response to ozone exposure, and is a response that will divert energy from primary metabolism. This has potential down-stream effects on productivity, in accordance with the growth difference balance hypothesis extended by Herms and Mattson (1992). Although it is evident that changing growth environments between controlled chambers and field-conditions has a bigger impact on transcriptome response for the model plant $A$. thaliana than does exposure to either increased ozone or $\mathrm{CO}_{2}$ (Miyazaki et al., 2004). Here differential gene expression was examined following acute ozone exposure in the indoor controlled environments while QTL were identified following chronic ozone exposure in the chambered field study. Although such out-door chambers do not reflect the true field conditions (Hendrey and Miglietta, 2006) this combination of approaches and an observed consistency between the selected genotypes within each experimental conditions provides a robust insight into transcriptome responses of Populus to tropospheric ozone.

In summary we have linked genetics and genomics to increase understanding of the control of adaptive responses to ozone in two Populus species and groups of $F_{2}$ genotypes that exhibit divergent sensitivities to acute and chronic ozone treatment. QTL mapping identified regions of the genome involved in trait expression, including those specific to ozone stressed plants. Genes such as SAM synthetase, a chitinase gene, Beta-1,3-Glucanase and Stable protein 1 exhibited expression differences between sensitivity groups and were found to co-localise to QTL for necrotic damage, providing encouraging evidence for their importance in governing this trait.

\section{Acknowledgements}

This research was supported by grants to G. Taylor from the European Commission through the Directorate General Research within the Fifth Framework for Research Quality of Life and Management of the Living Resources Programme, contract QLK5CT-2002-00953 (POPYOMICS), coordinated by the University of Southampton. GT wishes to acknowledge financial support from the Network of Excellence EVOLTREE, contract no. 016322, which is financially supported by the European Commission under the 6th Framework Programme, priority 6: Sustainable development, Global Change and Ecosystems. NRS and JT acknowledge studentships from the National Environment Research Council (ref NER/S/ A/2001/06361). JK acknowledges financial support from the 
Academy of Finland (Finnish Centre of Excellence program 2000 to 2005, and 2006 to 2011). We thank Jerry Tuskan for use of the Family 331 genetic map used for QTL mapping.

\section{Appendix. Supplementary material}

Supplementary material associated with this article can be found in the online version, at doi:10.1016/j.envpol.2010.09.027.

\section{References}

Berrang, P., Karnosky, D.F., Bennett, J.P., 1991. Natural selection for ozone tolerance in Populus tremuloides: an evaluation of nationwide trends. Canadian Journal of Forest Research 21, 1091-1097.

Bohler, S., Bagard, M., Oufir, M., Planchon, S., Hoffmann, L., Jolivet, Y., Hausman, J. Dizengremel, P., Renaut, J., 2007. A DIGE analysis of developing poplar leaves subjected to ozone reveals major changes in carbon metabolism. Proteomics 7 , 1584-1599.

Borevitz, J., Liang, D., Plouffe, D., Chang, H., Zhu, T., Weigel, D., Berry, C., Winzeler, E., Chory, J., 2003. Large-scale identification of Single-Feature Polymorphisms in complex genomes. Genome Research 13, 513-523.

Bortier, K., De Temmerman, L., Ceulemans, R., 2000. Effects of ozone exposure in open-top chambers on poplar (Populus nigra) and beech (Fagus sylvatica): a comparison. Environmental Pollution 109, 509-516.

Box, G.E.P., Cox, D.R., 1964. An analysis of transformations. Journal of the Roya Statistical Society, Series B 26, 211-252.

Bradshaw, H.D., Villar, M., Watson, B.D., Otto, K.G., Stewart, S., Stettler, R.F., 1994 Molecular-genetics of growth and development in populus.3. A genetic-linkage map of a hybrid Poplar Composed of Rflp, Sts, and Rapd Markers. Theoretical and Applied Genetics 89, 167-178.

Broadmeadow, M.S.J., Heath, J., Randle, T.J., 1999. Environmental limitations to ozone uptake - some key results from young trees growing at elevated $\mathrm{CO}_{2}$ concentrations, Water, Air, \& Soil Pollution 116, 299-310.

Broadmeadow, M.S.J., Jackson, S.B., 2000. Growth responses of Quercus petraea, Fraxinus excelsior and Pinus sylvestris to elevated carbon dioxide, ozone and water supply. New Phytologist 146, 437-451.

Brosché, M., Vinocur, B., Alatalo, E., Lamminmaki, A., Teichmann, T., Ottow, E. Djilianov, D., Afif, D., Altman, M.A., Polle, A., Dreyer, E., Rudd, S., Paulin, L. Auvinen, P., Kangasjarvi, J., 2005. Gene expression and metabolite profiling of Populus euphratica growing in the Negev desert. Genome Biology 6, R101.

Brunner, A.M., Busov, V.B., Strauss, S.H., 2004. Poplar genome sequence: functional genomics in an ecologically dominant plant species. Trends in Plant Science 9, $49-56$

Churchill, G.A., Doerge, R.W., 1994. Empirical threshold values for quantitative trait mapping. Genetics 138, 963-971

Coleman, M.D., Isebrands, J.G., Dickson, R.E., Karnosky, D.F., 1995. Photosynthetic productivity of aspen clones varying in sensitivity to tropospheric ozone. Tree Physiology 15, 585-592.

Conklin, P.L., Last, R.L., 1995. Differential accumulation of antioxidant mRNAs in Arabidopsis thaliana exposed to ozone. Plant Physiology 109, 203-212.

Degl'Innocenti, E., Guidi, L., Soldatini, G., 2007. Effects of elevated ozone on chlorophyll a fluorescence in symptomatic and asymptomatic leaves of two tomato genotypes. Biologia Plantarum 51, 313-321.

Déjardin, A., Leplé, J.-C., Lesage-Descauses, M.-C., Costa, G., Pilate, G., 2004 Expressed sequence tags from poplar wood tissues - a comparative analysis from multiple libraries. Plant Biology 6, 55-64.

Denman, K.L., Brasseur, G., Chidthaisong A., Ciais, P., Cox, P.M., Dickinson, R.E. Hauglustaine, D., Heinze, C., Holland, E., Jacob, D., Lohmann, U., Ramachandran, S., Da Silva Dias, P.L., Wofsy, S.C., Zhang, X., 2007. Couplings between changes in the climate system and biogeochemistry. In: Solomon, D. Qin, M., Manning, Z., Chen, M., Marquis, K.B., Averyt, M., Tignor, H.L., Miller (Eds.), Climate change 2007: the physical science basis. Contribution of Working Group I to the Fourth Assessment Report of the Intergovernmental Panel on Climate Change. Cambridge University Press, New York.

Fowler, D., Cape, N., Coyle, M., Flechard, C., Kuylenstierna, J., Hicks, K., Derwent, D., Johnson, C., Stevenson, D., 1999. The global exposure of forests to air pollutants. Water, Air, and Soil Pollution 116, 5-32.

Frei, M., Tanaka, J.P., Wissuwa, M., 2008. Genotypic variation in tolerance to elevated ozone in rice: dissection of distinct genetic factors linked to tolerance mechanisms. Journal of Experimental Botany 59, 3741-3752.

Fry, S.C., Dumville, J.C., Miller, J.G., 2001. Fingerprinting of polysaccharides attacked by hydroxyl radicals in vitro and in the cell walls of ripening pear fruit. Biochemistry Journal 357, 729-737.

Glick, R.E., Schlagnhaufer, C.D., Arteca, R.N., Pell, E.J., 1995. Ozone-induced ethylene emission accelerates the loss of ribulose-1,5-bisphosphate carboxylase/oxygenase and nuclear-encoded mrnas in senescing potato leaves. Plant Physiology 109, 891-898.

Gupta, P., Duplessis, S., White, H., Karnosky, D.F., Martin, F., Podila, G.K., 2005. Gene expression patterns of trembling aspen trees following long-term exposure to interacting elevated $\mathrm{CO} 2$ and tropospheric ozone. New Phytologist 167, $129-142$
Harper, A.D., Bar-Peled, M., 2002. Biosynthesis of UDP-xylose. Cloning and characterization of a novel Arabidopsis gene family, UXS, encoding soluble and putative membrane-bound UDP-glucuronic acid decarboxylase isoforms. Plant Physiology 130, 2188-2198.

Heggestad, H., Middleton, J., 1959. ozone in high concentrations as cause of tobacco leaf injury. Science 129, 208-210.

Hendrey, G.R., Miglietta, F., 2006. FACE technology: past, present and future. In: Nösberger, J., Long, S.P., Norby, R.J., Stitt, M., Hendrey, G.R., Blum, H. (Eds.), Ecological Studies. Managed Ecosystems and $\mathrm{CO}_{2}$ Case Studies, Processes and Perspectives, vol. 187. Springer-Verlag, Berlin Heidelberg.

Herms, D.A., Mattson, W.J., 1992. The dilemma of plants: to grow or defend. The Quarterly Review of Biology 67, 283-335.

Kargiolaki, H., Osborne, D., Thompson, F., 1991. Leaf abscission and stem lesions (intumescences) on poplar clones after $\mathrm{SO}_{2}$ and ozone fumigation: a link with ethylene release? Journal of Experimental Botany 42, 1189-1198.

Karnosky, D.F., Gagnon, Z.E., Dickson, R.E., Coleman, M.D., Lee, E.H., Isebrands, J.G., 1996. Changes in growth, leaf abscission, and biomass associated with seasonal tropospheric ozone exposures of Populus tremuloides clones and seedlings. Canadian Journal of Forest Research 26, 21-37.

Karnosky, D.F., Zak, D.R., Pregitzer, K.S., Awmack, C.S., Bockheim, J.G., Dickson, R.E. Hendrey, G.R., Host, G.E., King, J.S., Kopper, B.J., Kruger, E.L., Kubiske, M.E., Lindroth, R.L., Mattson, W.J., McDonald, E.P., Noormets, A., Oksanen, E., Parsons, W.F.J., Percy, K.E., Podila, G.K., Riemenschneider, D.E., Sharma, P., Thakur, R.C., Sober, A., Sober, J., Jones, W.S., Anttonen, S., Vapaavuori, E., Mankovska, B., Heilman, W.E., Isebrands, J.G., 2003. Tropospheric ozone moderates responses of temperate hardwood forests to elevated $\mathrm{CO}_{2}$ : a synthesis of molecular to ecosystem results from the AspenFACE project. Functional Ecology 17, 289-304.

Karnosky, D.F., Pregitzer, K.S., Zak, D.R., Kubiske, M.E., Hendrey, G.R., Weinstein, D., Nosal, M., Percy, K.E., 2005. Scaling ozone responses of forest trees to the ecosystem level in a changing climate. Plant, Cell and Environment 28, 965-981.

Kent, W.J., 2002. Blat-the blast-like alignment tool. Genome Research 12, 656-664.

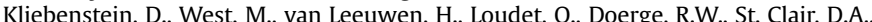
2006. Identification of QTLs controlling gene expression networks defined a priori. BMC Bioinformatics 7, 308.

Koch, J., Creelman, R., Eshita, S., Seskar, M., Mullet, J., Davis, K., 2000. Ozone sensitivity in hybrid poplar correlates with insensitivity to both salicylic acid and jasmonic acid. The role of programmed cell death in lesion formation. Plant Physiology 123, 487-496.

Lafarguette, F., Leple, J., Dejardin, A., Laurans, F., Costa, G., Pilate, G., 2004. Poplar genes encoding fasciclin-like arabinogalactan proteins are highly expressed in tension wood. New Phytologist 164, 107-121.

Langebartels, C., Kerner, K., Leonardi, S., Schraudner, M., Trost, M., Heller, W. Sandermann, H., 1991. Biochemical plant responses to ozone: I. Differential induction of polyamine and ethylene biosynthesis in tobacco. Plant Physiology 95, 882-889.

Langebartels, C., Wohlgemuth, H., Kschieschan, S., Grun, S., Sandermann, H., 2002. Oxidative burst and cell death in ozone-exposed plants. Plant Physiology and Biochemistry 40, 567-575.

Li, P., Mane, S., Sioson, A., Robinet, C., Heath, L., Bohnert, H., Grene, R., 2006. Effects of chronic ozone exposure on gene expression in Arabidopsis thaliana ecotypes and in Thellungiella halophila. Plant, Cell and Environment 29, 854-868.

Lindroth, R.L., 2010. Impacts of elevated atmospheric $\mathrm{CO}_{2}$ and ozone on forests: phytochemistry, trophic interactions, and ecosystem dynamics. Journal of Chemical Ecology 36, 2-21.

Lorenzini, G., Guidi, L., Nali, C., Soldatini, G., 1999. Quenching analysis in poplar clones exposed to ozone. Tree Physiology 19, 607-612.

Ludwikow, A., Gallois, P., Sadowski, J., 2004. Ozone-induced oxidative stress response in Arabidopsis: transcription profiling by microarray approach. Cellular and Molecular Biology Letters 9, 829-842.

Maere, S., Heymans, K., Kuiper, M., 2005. BiNGO: a Cytoscape plugin to assess overrepresentation of gene ontology categories in biological networks. Bioinformatics 21, 3448-3449.

Mahalingam, R., Jambunathan, N., Gunjan, S., Faustin, E., Weng, H., Ayoubi, P., 2006. Analysis of oxidative signalling induced by ozone in Arabidopsis thaliana. Plant Cell and Environment 29, 1357-1371.

Matsuyama, T., Tamaoki, M., Nakajima, N., Aono, M., Kubo, A., Moriya, S., Ichihara, T., Suzuki, O., Saji, H., 2002. cDNA microarray assessment for ozone-stressed Arabidopsis thaliana. Environmental Pollution 117, 191-194.

Miller, P.R., Parmeter, J.R., Taylor, O.C., Cordiff, E.A., 1963. Ozone injury to the foliage of Ponderosa pine. Phytopathology 53, 1072-1076.

Miyazaki, S., Fredricksen, M., Hollis, K.C., Poroyko, V., Shepley, D., Galbraith, D.W., Long, S.P., Bohnert, H.J., 2004. Transcript expression profiles of Arabidopsis thaliana grown under controlled conditions and open-air elevated concentrations of $\mathrm{CO}_{2}$ and of ozone. Field Crops Research 90, 47-59.

Overmyer, K., Brosche, M., Pellinen, R., Kuittinen, T., Tuominen, H., Ahlfors, R., Keinänen, M., Saarma, M., Scheel, D., Kangasjarvi, J., 2005. Ozone-induced programmed cell death in the Arabidopsis radical-induced cell death1 Mutant. Plant Physiology 137, 1092-1104.

Overmyer, K., Kollist, H., Tuominen, H., Betz, C., Langebartels, C., Wingsle, G., Kangasjarvi, S., Brader, G., Mullineaux, P., Kangasjarvi, J., 2008. Complex phenotypic profiles leading to ozone sensitivity in Arabidopsis thaliana mutants. Plant Cell and Environment 31, 1237-1249. 
Pandey, S., Ranade, S., Nagar, P., Kumar, N., 2000. Role of polyamines and ethylene as modulators of plant senescence. Journal of Biosciences 25, 291-299.

Piikki, K., Sellden, G., Pleijel, H., 2004. The impact of tropospheric ozone on leaf number duration and tuber yield of the potato (Solanum tuberosum L.) cultivars Bintje and Kardal. Agriculture, Ecosystems and Environment 104, 483-492.

Puckette, M.C., Tang, Y., Mahalingam, R., 2008. Transcriptomic changes induced by acute ozone in resistant and sensitive Medicago truncatula accessions. BMC Plant Biology 8, 46.

Rae, A.M., Robinson, K.M., Street, N.R., Taylor, G., 2004. Morphological and physiological traits influencing biomass productivity in short-rotation coppice poplar. Canadian Journal of Forest Research 34, 1488-1498.

Rae, A.M., Street, N.R., Robinson, K.M., Harris, N., Taylor, G., 2009. Five QTL hotspots for yield in short rotation coppice bioenergy poplar: the poplar biomass loci. BMC Plant Biology 9, 23.

Rinaldi, C., Kohler, A., Frey, P., Duchaussoy, F., Ningre, N., Couloux, A., Wincker, P., Thiec, D.L., Fluch, S., Martin, F., Duplessis, S., 2007. Transcript profiling of poplar leaves upon infection with compatible and incompatible strains of the foliar rust Melampsora larici-populina. Plant Physiology 144, 347-366.

Schultz, C.J., Johnson, K.L., Currie, G., Bacic, A., 2000. The classical arabinogalactan protein gene family of Arabidopsis. Plant Cell 12, 1751-1768.

Seaton, G., Haley, C.S., Knott, S.A., Kearsey, M., Visscher, P.M., 2002. QTL Express: mapping quantitative trait loci in of simple and complex pedigrees. Bioinformatics 18 , 339-340.

Shannon, P., Markiel, A., Ozier, O., Baliga, N.S., Wang, J.T., Ramage, D., Amin, N., Schwikowski, B., Ideker, T., 2003. Cytoscape: a software environment for integrated models of biomolecular interaction networks. Genome Research 13, 2498-2504.

Smyth, G.K., Speed, T., 2003. Normalization of cDNA microarray data. Methods 31, 265-273.

Street, N.R., Skogstrom, O., Sjodin, A., Tucker, J., Acosta, M., Nilsson, P., Jansson, S., Taylor, G., 2006. The genetics and genomics of the drought response in Populus. Plant Journal 48, 321-341.

Tallis, M.J., Yunan, L., Rogers, A., Zhang, J., Miglietta, F., Street, N.R., DeAngelis, P., Taylor, G., 2010. The transciptome of Populus in elevated $\mathrm{CO}_{2}$ reveals increased anthocyanin biosynthesis during delayed autumnal senescence. New Phytologist $186,415-428$.

Tamaoki, M., Nakajima, N., Kubo, A., Aono, M., Matsuyama, T., Saji, H., 2003a. Transcriptome analysis of ozone-exposed Arabidopsis reveals that multiple signal pathways act mutually antagonistically to induce gene expression. Plant Molecular Biology 53, 443-456.

Tamaoki, M., Matsuyama, T., Kanna, M., Nakajima, N., Kubo, A., Aono, M., Saji, H. 2003b. Differential ozone sensitivity among Arabidopsis accessions and its relevance to ethylene synthesis. Planta $216,552-560$.
Taylor, G., 2002. Populus: Arabdiospis for forestry. Do we need a model tree? Annals of Botany 90, 681-689.

Tuskan, G.A., Difazio, S., Jansson, S., Bohlmann, J., Grigoriev, I., Hellsten, U., Putnam, N. Ralph, S., Rombauts, S., Salamov, A., Schein, J., Sterck, L., Aerts, A., Bhalerao, R.R. Bhalerao, R.P., Blaudez, D., Boerjan, W., Brun, A., Brunner, A., Busov, V. Campbell, M., Carlson, J., Chalot, M., Chapman, J., Chen, G.L., Cooper, D., Coutinho, P.M., Couturier, J., Covert, S., Cronk, Q., Cunningham, R., Davis, J., Degroeve, S., Dejardin, A., Depamphilis, C., Detter, J., Dirks, B., Dubchak, I., Duplessis, S., Ehlting, J., Ellis, B., Gendler, K., Goodstein, D., Gribskov, M. Grimwood, J., Groover, A., Gunter, L., Hamberger, B., Heinze, B., Helariutta, Y., Henrissat, B., Holligan, D., Holt, R., Huang, W., Faridi, I., Jones, S., Rhoades, J. Jorgensen, R., Joshi, C., Kangasjarvi, J., Karlsson, J., Kelleher, C., Kirkpatrick, R. Kirst, M., Kohler, A., Kalluri, U., Larimer, F., Mack, L., Leple, J.C., Locascio, P., Lou, Y, Lucas, S., Martin, F., Montanini, B., Napoli, C., Nelson, D.R., Nelson, C., Nieminen, K., Nilsson, O., Pereda, V., Peter, G., Philippe, R., Pilate, G., Poliakov, A., Razumovskaya, J., Richardson, P., Rinaldi, C., Ritland, K., Rouze, P., Ryaboy, D., Schmutz, J., Schrader, J., Segerman, B., Shin, H., Siddiqui, A., Sterky, F., Terry, A., Tsai, C.J., Uberbacher, E., Unneberg, P., Vahala, J., Wall, K., Wessler, S., Yang, G., Yin, T. Douglas, C., Marra, M., Sandberg, G., Van de Peer, Y., Rokhsar, D., 2006. The genome of black cottonwood, Populus trichocarpa (Torr. \& Gray). Science 313, 1596-1604.

Utz, F.H., Melchinger, A.E., Schon, C.C., 2000. Bias and sampling error of the estimated proportion of genotypic variance explained by quantitative trait loci determined from experimental data in maize using cross validation and validation with independent samples. Genetics 154, 1839-1849.

Vahisalu, T., Kollist, H., Wang, Y.-F., Chan, W.-Y., Valerio, G., Lamminmäki, A. Brosché, M., Moldau, H., Desikan, R., Schroeder, J.I., Kangasjärvi, J., 2008. SLAC1 is required for plant guard cell S-type anion channel function in stomatal signalling. Nature 452, 487-491.

Wittig, V.E., Ainsworth, E.A., Naidu, S.L., Karnosky, D.F., Long, S.P., 2009. Quantifying the impact of current and future tropospheric ozone on tree biomass, growth physiology and biochemistry: a quantitative meta-analysis. Global Change Biology 15, 396-424.

Wohlgemuth, H., Mittelstrass, K., Kschieschan, S., Bender, J., Weigel, H.J., Overmyer, K., Kangasjarvi, J., Sandermann, H., Langebartels, C., 2002. Activation of an oxidative burst is a general feature of sensitive plants exposed to the air pollutant ozone. Plant, Cell and Environment 25, 717-726.

Woo, S.Y., Hinckley, T.M., 2005. The effects of ozone on growth and stomatal response in the $\mathrm{F}_{2}$ generation of hybrid poplar (Populus trichocarpa $\mathrm{x} P$. deltoides). Biologia Plantarum 49, 395-404.

Wullschleger, S., Jansson, S., Taylor, G., 2002. Genomics and forest biology: Populus emerges as the perennial favourite. Plant Cell 14, 2651-2655.

$\mathrm{Xu}, \mathrm{S}$., 2003. Theoretical basis of the Beavis effect. Genetics 165, 2259-2268. 